guna mural y de temas costumbrista moralizante. Se trata de un espléndido dibujo ejecutado al carbón, con ágiles trazos y acusado sombreado, que titulamos Mujer sentada pensativa, temática que acostumbró a representar referida a damas llenas de ausencia, serenidad y melancolía, que se atempera con unos aislados toques de color ${ }^{31}$.

Nuevamente aparece retratado Guillermo de Osma en un aterciopelado dibujo realizado al carbón por Agustín Almar ${ }^{32}$, que se había formado en la segunda mitad del siglo xix en la valenciana Academia de Bellas Artes de San Carlos, pintor de asuntos costumbristas y ceramista, en función de cuya actividad debió trabar relación con el retratado, que era experto coleccionista en la materia, como lo prueba la dedicatoria que figura al pie ${ }^{33}$.

Restan por citar dos piezas que podrían datarse a fines del xIx o principios del xx. La primera es un expresivo y atractivo dibujo al carbón ${ }^{34}$, de correctísima ejecución plástica, al estilo de Ramón Casas (1866-1932), que refleja la serenidad y clase de la Dama retratada, cuya firma, de trazo poco claro, aunque parece A. de Baviu, ofrece dudas a la hora de hacer una atribución segura. No obstante, por las características plásticas de la obra, podría ser Antonia de Bañuelos y Tourdike, pintora de la segunda mitad del siglo xix, formada en Roma y París, especialista en retratos, que participó en las Exposiciones de Bellas Artes (1878 y 1880) y en la Universal (1889), ambas de París, así como en las Nacionales de 1887 y 1890 en las que recibió mención honorífica y segunda medalla, respectivamente ${ }^{35}$. El segundo, y último, es un anónimo Paisaje, ejecutado con soltura en el uso del lápiz mediante un procedimiento simple, consistente en trazos paralelos degradados con los cuales se consigue la volumetría de las formas, y que posiblemente formó parte del típico cuaderno de apuntes de campo, a tenor del número que figura en uno de sus extremos ${ }^{36}$.

José Antonio Ocaña Martínez

C.S.I.C.

\title{
DOCUMENTOS INÉDITOS PARA LA BIOGRAFÍA DE LOS MACIP *
}

La importante exposición sobre Vicente Macip realizada en el Museo de Bellas Artes de Valencia en 1997, acompañada del extenso catálogo ' con textos de su comisario el doctor Fernando Benito y de José Luis Galdón, ha supuesto, desde su rigurosa tarea de investigación, la

${ }^{31} \mathrm{~N}^{\circ}$ inv. $^{\circ} \mathrm{I}-7869,457 \times 524 \mathrm{~mm}$, lápiz carbón con toques de cera azul y ocre sobre papel. Fd. ${ }^{\circ}$ a.s.d. «Juan Llimona».

32 VV. AA, Cien años de pintura en España y Portugal, 1830-1930, Anticuaria, op. cit., vol. I, pp. 130-131; Garín Ortiz, F., Catálogo-Guía del Museo de Bellas Artes de San Carlos de Valencia, Inst. Alfonso el Magnánimo, Valencia, 1955, p. 207; Tormo, E., Valencia, los museos de Valencia, Valencia, 1932, p. 73.

${ }_{33}$ N. ${ }^{\circ}$ inv. I-6215, 460 x 294 mm, carbón sobre papel Sucesores de Torras. En a.i.d. «A. Almar. Al Instituto de Valencia de Don Juan». No debe descartarse la posibilidad de que este retrato haya sido realizado a partir de una de las abundantes fotografías que se conservan de G. de Osma, muchas de ellas en el Instituto, lo que no resta calidad alguna al dibujo.

${ }^{34} \mathrm{~N}$. $^{\circ}$ inv. $^{\circ} \mathrm{I}-6311,320 \times 230 \mathrm{~mm}$, carbón sobre papel y ligera aguada. En a.i.d. «¿A de Bañuelos»?

35 Osorio y Bernard, M., Galería Bibliográfica de Artistas españoles del s. XIX, op. cit, p. 67; Pantorba, B. de, Historia y crítica de las exposiciones nacionales de Bellas Artes, Madrid, 1980, op. cit, p. 373 y VV. AA, Cien años de pintura en España y Portugal, 1830-1930, Anticuaria, op. cit. Vol. I, p. 262.

${ }_{36} \mathrm{~N}^{\circ}$ inv. $^{\circ} \mathrm{I}-7867,161 \times 272 \mathrm{~mm}$, lápiz sobre papel. En a.s.d. «12» a lápiz.

* Agradezco a M. José López Azorín, la fundamental aportación documental para la elaboración de este artículo, y a Eva M. ${ }^{a}$ García Barambio la transcripción de gran parte de estos documentos. Queremos señalar que este artículo se redactó con anterioridad a la exposición Joan de Joanes. Una nueva visión del artista y su obra inaugurada en enero de 2000 en el Museo de Bellas Artes de Valencia. Consideramos entonces, al saber que se estaba preparando esta muestra, que era oportuno entregar a sus responsables una copia del artículo, apareciendo debidamente citado en su catálogo como «en publicación» - pues había sido ya aceptada su publicación en esta revista- De este catálogo extrae algún dato L. Hernández Guardiola para un artículo sobre Jerónimo de Córdoba, citando también adecuadamente la fuente.

1 Vicente Macip (h.1475-1550). Museo de Bellas Artes de Valencia, febrero-abril de 1997. 
recuperación de un pintor cuya gran parte de su producción había sido ignorada y confundida por la historiografía. Ignorada por lo que se refiere a su trayectoria en su etapa «joven» $y$, confundida, por haberse visto su nombre ensombrecido por la arrolladora presencia de su hijo, el conocido Joan de Joanes. De esta forma se presentaba, sin duda, a uno de los mejores pintores del Renacimiento hispano, planteando por vez primera una propuesta de reconstrucción de su vida profesional, desde sus inicios en el gótico cuatrocentista de fines de siglo xv hasta su incipiente etapa manierista, explicando las influencias que pintores como Paolo de San Leocadio, los Hernandos y Sebastiano del Piombo pudieron ejercer en su arte.

La relación documental que aquí presentamos se inicia con un acto notarial de $1495^{2}$ que recoge la cancelación de la dote matrimonial firmada en 1493 entre Vicente Macip e Isabel Navarro. El documento notarial nos dice textualmente en algunos de sus párrafos: Sit omnibus notum quod ego, Vincentius Macip, pictor retabilis Valentia vicinus, scienter et in veritatis recognosco vobis, honorabilis Ysabel, uxor mee, filii Miquelis Navarro, laborator, quondam, presenti et ... modo infrascripto, dedicto et soluptio mehi ... quinquaginta libras moneda real Valentia ... institutio et portatio et instrumento publico recepto por Ludovico Spinal notario infrascriptum quarto die mensis Septembris anno 1493 ... Entendemos que su interés radica en que en 1493 Macip ya es pintor de retablos, adelantando varios años la primera fecha en la que aparecía como tal, por lo que contaría ya por entonces con la mayoría de edad, a la vez que manifiesta șu estado civil de casado. Por ello, deducimos que su fecha de nacimiento debe situarse, de momento, hacia 1468-70.

El siguiente documento corresponde al testamento de su esposa Isabel Navarro en 1544, cinco días antes de morir ${ }^{3}$. Este acto jurídico es similar al que su marido realizaría un año más tarde y ante el mismo notario ${ }^{4}$, no sólo en lo referente a sus claúsulas sino también en las disposiciones. De este documento destacamos los nombramientos como albaceas, ... als Reverent mestre Domingo // Sarmiento, prevere, mestre en Sacra Teologia, beneficiat en la metropolitana Seu de la present ciutat de Valentia, confesor meu present, e lo honorable en Johan Macip, pintor fill meu molt amat e del dit marit meu, legitim e natural, habitadors de la dita present ciutat,... A su hija Isabel Macip de Buera, filla mia e del dit marit meu, legitima e natural,... le lega los cinco sueldos per part e per legitima, y a la hija de ésta - es decir, su nieta-, deja dos legados especiales: uno por unos servicios prestados y otro en contemplación de matrimonio, tal como nos dice:...a Mariana Buera, donzella, neta mia e filla de la honorable na Ysabel Macip de Buera, filla mia e del dit marit meu, legitima e natural, viuda, muller que fou del honorable en Miquel Buera, quondam, mercader, per molts bons serveys que yo de aquella he rebut ... Item leix e legue a la dita Mariana Buera, donzella neta mia, en contemplacio del matrimonio de aquella e no en altra manera, de mos bens, deu libres // de la dita moneda, lo qual legat li fas en paga y remuneracio dels serveys que aquella me ha fet fins en la present jornada e del hui avant fara. Como heredero de sus bienes, consta Vicent Macip, molt amat marit meu, especificándose que a la muerte de este

\footnotetext{
${ }^{2}$ Archivo del Reino de Valencia, Protocolos de Luis Espinal, n. ${ }^{\circ}$ 2883, 1495-96, 23 de febrero de 1495. (El subrayado es nuestro). La primera fecha en la que Vicente Macip aparecía como pintor de retablos (1501) es la ofrecida por Mercedes Gómez-Ferrer Lozano en «Nuevas noticias sobre el retablo de la vida de San Esteban de Joan de Joanes» en Boletín del Museo del Prado, 1995, p.13.

${ }^{3}$ Doc. 1. Archivo de Protocolos del Colegio del Patriarca, Valencia (en adelante APPV). Protocolos de Joan Guimera, n. ${ }^{\circ} 2701,7$ de noviembre de 1544. (El subrayado es nuestro). Queremos indicar que Domingo Sarmiento aparece en ciertos documentos de la época como ejecutor general y administrador de los últimos testamentos.

${ }^{4}$ Testamento publicado por el Barón de Alcahalí en Diccionario Biográfico de Artistas Valencianos, 1897, pp.158-160. Revisado este testamento, encontramos que la fecha de fallecimiento de Vicente Macip es el año 1551, no 1550 como se creía.
} 
pasen sus bienes al ...mestre Johan Macip, fill meu e del dit marit meu, legitim e natural... De esta forma, hallamos la composición de la familia Macip en estas fechas, con dos hijos y una nieta, junto a la filiación completa de Joan de Joanes: Joan Macip Navarro, a la vez que se descarta un segundo matrimonio de Vicente Macip, realizado, según la bibliografía, con Isabel Forner ${ }^{5}$.

Realmente, la relación entre Isabel Forner y Vicente Macip, se esclarece en el siguiente documento de $1550{ }^{6}$, con motivo de la venta de un censal sito en la localidad valenciana de Albaida, exactamente en la partida del Palomar, a Antonio Mico, labrador de esta villa, realizado unos meses antes de morir Macip, donde consta que: Ego Vicentius Macip, pictor, habitator civitatis Valentie, tamquam heres universalis et eo, nomine bonorum omnium et iurium que, quondam, fuerum honorabilis Ysabellis Forner, beate, filie honorabilis Gabrielis Forner, quondam pannorum paratoris, pro ut dedicta mea herencia constat cum eius ultimo testamento confecto Valentie per honorabilis et discretum Ludovicum Spinal, quondam, notario, recepto die sexto mensis augusti anno a Nativitate Domini millessimo quingentessimo sexto ... publicato die decimo sexto mensis februarii anno a Nativitate Domini millessimo quingentessimo vigesimo primo. Gratis, etc., dicto nomine per me et sucessores meos quos cumque vendo, concedo, trado, seu quasi trado, transfero, atque transporto vobis honorabilis Antonio Mico, agricole loci del Palomar, termini ville de Albayda, filii honorabilis Petri Mico, agricultoris eiusdem loci present, etc. Et vestris omnes illos viginti et quinqe solidos moneta regal Valentie, censuales, rendales et anuales, sine laudimio et fatica, etc, ... Et qui per honorabilis Bernardum Mico del Cafareig, agricultorem, et Ysabellem coniuges vicinosque et habitatores predicti loci del Palomar simul et in solidum fuerunt venditi et originaliter carricati prefate quondam Ysabelli Forner mediante publico venditionis et originalis carricamenti predicti censualis instrumento, acto in dicta villa de Albayda per honorabilem et discretum Bernardum Boyl, quondam, notarium recepto die decimo-sexto mensis octobris anno a Nativitate Domini millessimo quingentessimo primo. Pretio undecim librarum moneta pre//fixe.

El hecho de que Vicente Macip fuera desde 1506 el heredero universal de Isabel Forner, beata, es decir, vinculada a alguna orden religiosa, ya secular o regular, fallecida en 1521 según la publicación del testamento, con bienes en Albaida, indica una relación muy antigua y estrecha entre ambos, tal vez familiar.

Respecto a Joan Macip, aparece de nuevo en 1553, ya fallecido su padre, firmando con Joan de Cordova, el contrato de afermament del hijo de éste, llamado Jerónimo de Cordova, de 16 años, para formarse junto a Joan Macip en el artem pictoris por un periodo de seis años, obligándose además durante ese tiempo a calzarlo, vestirlo y darle todo lo necesario ${ }^{7}$.

\footnotetext{
${ }_{5}^{5}$ En los documentos que aquí presentamos en ningún momento se cita a Joanes con el nobre de Joan Vicente, sin embargo este nombre compuesto aparece en abundante documentación de la época. Véase lo referente a Isabel Forner en Sanchis Sivera, J.: Pintores medievales en Valencia, Valencia, 1930, p. 231.

${ }^{6}$ Doc. 2. A.P.P.V. Protocolos de Jeroni Massot, n. ${ }^{\circ}$ 15401, 16 de agosto de 1550. El subrayado es nuestro. Por otra parte, estos datos completan lo recogido sobre el censal del Palomar por Albi, J. en Juan de Juanes y su círculo artístico, Valencia, 1979 (3 vols.), p.14 y Benito, F. en el catálogo de la exposición Vicente Macip (h.1475-1550), p. 16.

7 Doc. 3. A.P.P.V. Protocolos de Jeroni Massot, n. ${ }^{\circ} 15.403,16$ de abril de 1553. En ésta época (1553-1559) aparecen documentados algunos de los trabajos de Joanes, como el retablo de San Antonio y Santa Bárbara de la Parroquia de Ntra. Señora de la Asunción de Onda (1558).

El pintor Joan de Cordova aparece recogido en los impuestos de Tacha Real, afincado en el término de la parroquia de San Martín (véase Falomir, M.: La pintura y los pintores en la Valencia del Renacimiento (1472-1620), Valencia, 1994, p. 99 y ss). En este tipo de contratos, de formación y tutelaje, existía una relación muy directa entre maestro y aprendiz, quien en ocasiones se hospedaba en la casa taller del pintor, convirtiéndose en poco menos que un criado, aunque beneficiándose también a menudo de pequeños salarios. Sobre la formación de los aprendices véase Falomir, M.: Arte en Valencia, 14721522, 1996, p.234-237. Por otra parte, debemos indicar que seis o cuatro años es el periodo de aprendizaje que se contempla en los estatutos (capítulo IV) del Colegio de Pintores que se había creado en 1520 (véase Benito, F.: «Un Colegio de
} 
Para concluir, debemos señalar que cinco años más tarde, figuran Jerónimo Cardona y Baptiste Steve, ambos pintores, como testigos del siguiente documento ${ }^{8}$. Se trata de una donación inter-vivos que realiza en 1558 Joan Macip, pictor, civitatis Valencie habitator, a Maria Ana Boera, filiam honorabilis Petri Boera, quondam, mercatoris ville de Albayda, virginem..., de un censal de 35 sueldos anuales de pensión, cargados sobre Pere Sans, presbiter, vicarius temporalis ecclesie eiusdem ville de Albayda. Además, se especifica que el censal fue cargado por la parroquia de esta villa en 1505 a favor de Isabel Forner, beata, por el precio de 21 libras, que pasaría a formar parte de la herencia recibida por Vicente Macip a la muerte de aque1la. Acompañan a esta donación el acuerdo y el nombramiento de un procurador entre ambas partes. Por todo ello, por la relación directa que como podemos ver Macip tuvo con Albaida, podemos pensar que el pintor, tal y como afirma el canónigo Vitoria ${ }^{9}$, bien pudo nacer en esta płbiblación, a falta de documentos más concluyentes.

Vicente SAmper EMbiz

1. 1544 , noviembre 7 . Valencia

Testamento de Isabel Navarro, mujer de Vicente Macip, pintor de la ciudad de Valencia. Archivo del Colegio del Patriarca, Valencia. Protocolos notariales (APPV), n.. 2.701 . Notario Joan Guimera.

Die VII mensis novembris anno millesimo DXLIV

En nom de la inmensa e individua Trinitat, Pare, Fill, Spirit Sant, tres persones un sols Deu tot poderos, e de la Sacratissima Verge Maria, mare de Deu e de misericordia y acvocada dels pecadors. Com no sia cosa mes certa en aquest mon quel haver de morir, ne mes incerta que la hora de la mort, per la cual raho de tota persona prudent e havent urs de raho, se pertanyga dispondre e ordenar // dels bens temporals que el Señor Deu Jesuchrist li haura acomanats en aquest mon de miseria, perque de aquells bon compte e raho ne puga donar en laltre mon per la divina maiestat li sera demanat per so, yo na Isabel Navarro, muller del honorable en Vicent Macip, pintor habitador de la present ciutat de Valencia, stant malalta en lo llit de greu malaltia, de la qual tem morir, estant empero per gracia de Nostre Señor en mon bon seny sana memoria entregalaga e manifesta paraula, casant, revocant e anullant tots e qualsevol testaments, codicilis e altra qualsevol ultima e darrera voluntat, permi fet e feta fins en la present jornada e feta en poder de qualsevol notari o notaris o (altra) en qualsevol altra forma e manera, ara de nou fas e ordene lo present meu ultim e darrer testament, ultima e darrera voluntat mia, en e per la forma inmediata seguent.

E primerament fas constituix e elegeix emmarmesors meus e del present meu ultim e darrer testament executor als Reverent mestre Domingo // Sarmiento, prevere, mestre en sacra teologia, beneficiat en la metropolitana Seu de la present ciutat de Valentia, confesor meu present, e lo honorable en Johan Macip, pintor fill meu molt amat e del dit marit meu, legitim e natural, habitadors de la dita present ciutat, absent, axi com si fos present, als quals en temps done licentia e facultat ple e bastant poder tans de mos bens pendre, e aquells vendre alienar e transportar, y los preus de aquells rebere per compte ...ner hagut e rebut sens licencia autoritat ne decret de juzge, alguasil eclesiastich com secular, que basten a pagar e cumplir les coses pies per mi de ius (dispostes e) ordenadores.

Item vull e mane que apropint quantse la hora de la mia mort e venint in extremis, me sia donat e liurat lo Sanct Sacrament de extrema unctio vulgarment apellat de peroliar, acompanyat ab dos preveres de la sglesia parrochial de Sancta Creu de la present ciutat de presente yo so paroquiana, als quals vull e mane sia pagada la cantitat acostumada.

Item vull e mane que apres que la mia // anima sera separada del meu cors, lo dit meu cors acompanyat ab tants preve-

pintores en la Valencia de 1520» en Archivo de Arte Valenciano, 1992, pp. 62-67, y en Falomir, op. cit., 1964, pp. 29 y ss y 102-105).

${ }^{8}$ Docs. 4 y 5 . La fecha del protocolo y el notario aparece recogido por Alcahalí, op.cit, p.161. Localizado en A.P.P.V., protocolos de Andrés Martín Pineda, n. ${ }^{\circ}$ 16.160, 23 de abril de 1558. Agradecemos al profesor Viçent Pons la revisión de la transcripción de este extenso y mal conservado documento.

Debemos indicar que este Pedro Buera, mercader, aparece en el anterior documento con el nombre de Miguel. Entendemos que se trata de la misma persona, tal vez de nombre compuesto, o bien podría ser un error del notario.

Por otro lado el apellido Cardona aparece en numerosas ocasiones. Existe un documentado Joan Cardona que fue Pintor de la Ciudad entre 1523 a 1543, citado por la historiografía, y que podemos ver en los impuestos de la época. Tuvo un hijo, también pintor, de nombre Bartolomé. También aparece un Francisco Cardona, pintor, decorando en 1491 la capilla de Lluis de Santangel en la iglesia del Monasterio de la Trinidad (Archivo del Reino de Valencia, Protocolo de Luis Espinalt, n. ${ }^{\circ}$ 3096, 1491-92).

9 Bassegoda, B.: «Vicente Vitoria (1650-1709), primer historiador de Joan de Joanes», Locus Amoenus, n. ${ }^{\circ} 1$, 1995, pp. $165-172$. 
res de la dita sglesia parroquial de sancta creu quants als dits meu marmessors ben vist sera sia portat a la sglesia del monestir de la Sacratissima Verge Maria del Carme y lo dit meu cors en aquella si se fera hora de mi pers, sia dita e celebrada per anima mia una misa baixa de requiem e apres de celebrada la dita misa lo dit mentos sia liurat a eclesiastica sepultura en lo vas o cimenteri del fratres e sino sera hora de mises vull e man que lo dit mentors sia liurat a eclesiastica sepultura en lo vas o cementeri dels fratres. E vull e man que per dita sepultura sia pagada la caritat acostumada e necessaria pregant molt als dits meus marmessors aquella faren molt plenament y sens pompa alguna. E vull, ordene e mane que per anima mia y en sufragi de aquella, per los dits meus marmesors sien presens de mos bens cent sous modeda reals de Valencia, dels quals vull e mane sien pagades totes les coses pies de sus dites e pagades les dites caritats e si alguna cosa restara o sobrara dels dits cent sous, vull e man que per los dits meus marmessors me sien fetes dits e celebrats tantes misses de requiem o de la devotio que als dits meus marmessors parexera e ben vist sera per anima mia y dels tots bons del defunts quant (esseporam..) per fer dit e celebrar les quals mises vull e man que sien dites e celebrades so es la mitat en la dita sglesia parrochial de Santa Creu y per les preveres de aquella, e altre mitat en la sglesia del monastir de la Verge Maria del Carme (...) y per los fratres de aquell e no en altra manera.

Item leix e legue al (baci de la redemsio).... los dits cent sous per anima mea pres sos al Spital General de la present ciutat de Valencia deu sous de la dita moneda en remisió de mos pecats per caritat e subvencio de la obra e pobres del dit Spital.

Item vull e mane que tots mos torts deutes e (iniuries) sien pagats e satisfets aquells e auqlles, empero que mostraran arbarans yo essen tenguda e obligada // ab cartes, albarans, testimonis e altres legitimes proves fer de anima e de bona consciencia sobre aso benignament observat.

Item leix e legue a Mariana Buera, donzella, netamia e filla de la honorable na Isabel Macip de Buera, filla mia e del dit marit meu, legitima e natural, viuda muller que fou del honorable en Miquel Buera, quondam, mercader, per molts bons serveys que yo de aquella he rebut e de (...) reber la present malaltia tres lensols delers(...) de casa usats de tres teles casa mei, una per a de torca bognes e altres coses de lens, les quals lensols per de torca bognes e altres coses de les quals (...) ninguna (...) leix e legue una catifa mig usada de forma mijana portoguesa, lo qual de presenti en torn del meu llit a fer de totes les dites coses a ser planes e liberes voluntats.

Item leix e legue a la dita Mariana Buera, donzella neta mia, en contemplacio del matrimonio de aquella e no en altra manera de mos bens deu libres // de la dita moneda, lo qual legat li fas en paga y remuneracio dels serveys que aquella me ha fet fins en la present jornada e del hui avant fara.

Item leix e legue a la dita Isabel Macip de Buera, filla mia e del dit marit meu, legitima e natural, cinc sous de la dita moneda per part e per legitima e per tot altre e qualsevol dret que aquella tinga e li pertanyga en mons bens y herentia.

Tots les altres bens meus, nobles, innobles, seents e semovents, deutes drets e accions a mi pertanyents e pertanyen, podents y devents, luny o prop, ara o en esdevenidor, per qualsevol titol, causa, via manera e raho hon se vulla, sien e seran e a mi pertanyguen e pertanyer, pugueu done e leixe al dit honorable en Vicent Macip, molt amat marit meu, e aquell hereu meu propri e universal, fac e institueixch en los dits bens e drets meus y herencia mia de vida de aquell, tans solament apres ab te de aquell hereu meu propri e universal fac e institueixch // en los dits bens e drets meus y herencia mia, e al dit marit meu y hereu meu subprimeix per lo dit mestre Johan Macip, fill meu e del dit marit meu, legitim e natural, y altre dels marmessors meus segons dits a fer de aquells a totes planes e liberes voluntats.

Aquest es lo meu ultim e darrer testament, ultima e darrera voluntat mia, lo qual e la qual vull e man voler e tenir per dret de darrer testament, codicilis, e altra qualsevol ultima e darrera voluntat mia, o per aquell dret que millos per furs e privilegis del present regne o altre de Iusticia valer e tenir per a les quals coses foren fetes, en la dita present ciutat de Valencia, a set dies del mes de novembre del any de la Nativitat del Nostre Senyor Deu Jesu Christ, Mil cinch cents quaranta quatre.

(Cruz) Deu in dita Ysabel Navarro e de Macip testadriu qui de suns qui les dites coses li e otorgue dispons e ordene.

Presents foren per testimonis convocats y pregats a la confessio del dit testament, los honorables en Indavell Super, Franciscus Pasqual e ur Bou Canyardo // (...) habitadors de Valencia, les quals, interrogats per lo notario davall dit si coneix la dita testaderiu, e tots dixerem que si, e la dita testaderiu, interrogada si coneixia als dits testimonis e dix que si, e yo dit notario coneg molt be a tots.

En apres a tretze dies del dit mes de novembre del mateix any de la Nativitat de Nostre Senyor Deu Jesuchrist es mil cinch cents quaranta quatre, que era lo tercer dia en apres que la di testadriu mori e passa de la present vida en laltra, lo preinsert testament e ultima voluntat de la dita Ysabel Navarro e de Macip, a instantia e requesta dels honorables en Vicent Macip, marit de la dita testadriu, e den Johan Macip, fill de aquells, en lo dit testament mentionats e en presentia de aquells ab altra veu e intelligible de la primera linea fins a la darrera inclusive, per mi, Johan Guimera, notari, rebedor de aquell fonch, lest e publicat e encontinent lest y publicat aquell // lo dit en Johan Macip dix que per amor e reverentia de Nostre Senyor Deu y per la molta voluntat que tenia a la dita defunta y mare de aquell, acceptava, axi com de fet accepta, lo carrec de la dit marmesoria, e lo dit en Vicent Macip dix que acceptava, com de fet accepta, la dita herentia, e lo dit en Johan Macip dix que acceptava la dita herencia e substitucio apres mort del dit marit, son pare. Et etiam diguerem los dits en Vicent Macip e Johan Macip que se aniran en acord a maior deliberacio sobre la confectio del inventari fahedor dels bens e drets de la dita herencia, protestant, com de fet protestaren, que en explicar dit acord, ne en la confesio del dit inventari tempo algu nols prerorrega aus tot son temps e dret los restasalvo a (lle) innonibus et per omnia de totes les quals coses requierem que per mi dit notario fora ... publich lo qual fonch rebut en la dita ciutat de Valencia dins la casa dels dits hereu hau hon la dita testadriu mori e passa de la present vida en laltra (los desus) dits dia, mes e anni // A la qual publicacio foren presents y testimonis los honorables (Emge) Torres, notario real, e Frances y Anari Martinez, velluter habitador de Valencia. 


\section{1550, agosto 16. Valencia}

Venta de un censal propiedad de Vicente Macip, heredado de Isabel Forner, beata, hija de Gabriel Forner, dorador de retablos, localizado en la partida del Palomar (Albaida), a Antonio Mico, agricultor de dicho término.

Archivo del Colegio del Patriarca, Valencia. Protocolos notariales (APPV), n. ${ }^{\circ}$ 15.401. Notario Jeroni Massot.

Die XVI mensis augusti anno a Nativitate Domini millessimo D. ${ }^{\circ} \mathrm{L}$

Ego, Vincentius Macip, pictor, habitator civitatis Valentie, tamquam heres universalis et eo, nomine bonorum omniumque, quondam, fuerum honorabilis Ysabellis Forner, beate, filie honorabilis Gabrielis Forner, quondam, pannorum paratoris, pro ut dedicta mea herencia constat cum eius ultimo testamento confecto Valentie per honorabilis et discretum Ludovicum Spinal ,quondam, notario, recepto die sexto mensis augusti anno a Nativitate Domini millessimo quingentessimo sexto ac per eundem notarium // post dictae testadiris mortem, publicato die decimo sexto mensis februarii anno a Nativitate Domini millessimo quingentessimo vigesimo primo. Gratis, etc., dicto nomine per me et successores meos quos cumque, vendo, concedo, trado, seu quasi trado, transfero, atque transporto vobis honorabilis Antonio Mico, agricole loci del Palomar, termini ville de Albayda, filii honorabilis Petri Mico, agricultoris eiusdem loci, presenti, etc. Et vestris omnes illos viginti et quinqe solidos moneta regal Valentie, censuales, rendales et anuales, sine laudimio et fatica, etc, annis singulis solvendos die decimo sexto mensis octobris unica solutione. Et qui per honorabilis Bernardum Mico del Cafareig, agricultorem, et Ysabellem, coniuges, vicinosque et habitatores predicti loci del Palomar simul et in solidum fuerunt venditi et originaliter carricati prefate quondam Ysabelli Forner mediante publico venditionis et originalis carricamenti predicti censualis instrumento, acto in dicta villa de Albayda per honorabilem et discretum Bernardum Boyl, quondam, notarium, recepto die decimo-sexto mensis octobris anno a Nativitate Domini millessimo quingentessimo primo. Precio undecim librarum moneta pre//fixe. Iam dictos itaque viginti et quinque solidos dicta monetae censuales vobis et vestris vendo unacum pensione et porrata eorundem usque in hunc currentem et hodierdum diem debitis atque de cursis pretio videlicet decem et septem librarum et quinque solidum monete precontentae, quas et quos dicto nomine confiteor a vobis habuisse et recepisse ad meam omnimodam voluntatem realiter numerando in presentia notari et testium infrascriptorum. Unde renunccio scienter omni exceptioni venditionis predictae per me iam dicto nomine vobis non facta pecunieque predictae pro pretio et nomine precii dictae venditionis a vobis non habite, etc., ut predicitur et doli legi sive foro, etc. Dans atque remittens, etc., et ex causa omni modi venditionis dicto nomine. Do, cedo, etc., quibus iuribus etc., instituens, etc., ad habendum, etc., exceptis clericis, etc., nisi, etc. In iugens, etc., pro ut melius etc., promittens, etc., protestor tamen quod non tenear nec teneri volo vobis et vestris de firma et legali evictione nec ad alicuius quantitatis restitutionem nisi precise et dum (...) ac pro factis, contractibus et obligationibus // dicte herencia et non pro aliis aliter nec alias ullomodo. Pro quibus tantum obligo omnia bona et iura herenciae predictae mobilia, etc. Actum, etc. Valentie, etc.

Testes huius rei sunt honorabilis Michael Soler, agricultor loci de Agullent pro nunc Valentie personaliter residens et Joannes Enyigues, cabanierius civitatis Valentie habitatores.

Ffiat apoca de dicto pretio habito realiter numerando in presencia notarii et testium infrascriptorum. Et quia, etc. Renuncio, etc. Ffaciens, etc. Actum ut scriptorum.

Testes qui supra.

\section{1553 , abril 16. Valencia}

«Afermament» de Hieronimum de Cordova, de 16 años, para aprender al arte de la pintura, con Joan Macip, pintor de Valencia, realizado entre éste y Joan de Cordova, pintor de dicha ciudad, padre de aquel, por un periodo de seis años.

Archivo del Colegio del Patriarca, Valencia. Protocolos notariales (APPV), n. ${ }^{\circ}$ 15.403. Notario Jeroni Massot

Die XVI mensis aprilis anno a Nativitate Domini millessimo D. ${ }^{\circ}$ LIII. ${ }^{\circ}$

Ego Joannes de Cordova, pictor, habitator civitatis Valentie. Gratis, etc, mitto et affirmo vobis cum honorabilis Joanne Macip, ectam pictore, eiusdem civitatis habitatoris, presente, etc, Hieronimum de Cordova, filium meum, etatis sexdecim annorum parum plus anti minus, ad serviendum vobis et familie vostre et ad faciendum omnia mandata vestra licita tamen et honesta, et quod teneamini ostendere ei artem vestram pictoris a tempus sex annorum computandorum a die primo men//sis martii proxime preteriti continuo, In antea itaque durante tempore predictorum sexannorum tenea mini eum tenere sanum et egrum et calciare et vestire eum et dare sibi omnia alia necessaria ad eius vitam ducendam tempore vero infinitatis tempore sanitatis pro uno die, duos ut moris est emendando et refficiendo. Cum hoc siquidem pacto videlicetque. In fine dicti temporis non teneamini aliquid ei dare pro solidata tam in peccunia numerata quam In raupis novis, Promittens, etc. Obligans, etc. Ad hec autem, ego dictus Joannes Macip, pictor, presens, suscipiensque et acceptans dictum Hieronimum de Cordova in famulum et servitialem meum, promitto vobis prefato Joannii de Cordova eius patri presenti etc. predictum Hieronimum de Cordova, filium vestrum tenere sanum et egrum calciareque et vestire eum et dare sibi omnia alia necessaria ad eius vitam, ducendam, prototo tempore predictorum sexannorum computandorum ut dictum est. Et etiam promitto ostendere ei dictam meam artem pictoris, cum hoc videlicet pacto et non sine eo, aliter nec aliasquod in fine dicti temporis non tenear necque ...moxuis et obligatus dare et persolvere ei // aliquid pro solidata pro ut superius dictum est cum sic inter me et vos prefatum Ioannem de Cordova conventum atque pactatum exciterit. Promitens, etc. Obligans, etc. Actum, etc. Valentie, etc.

Testes huius rei sunt honorabiles Joannes Palau, scriptor, et Ffraciscus Pallares, passamanerius, civitatis Valentie habitatores. 
4. 1558 , abril 23. Valencia

Donación inter-vivos realizada por Joan Macip, pintor de la ciudad de Valencia a Maria Ana Boera, hija de Pedro Boera, fallecido, mercader de la villa de Albaida.

Archivo del Real Colegio del Corpus Christi de Valencia. Protocolos Notariales de Andrés Martín Pineda, n. ${ }^{\circ} 16.160$.

Cit. en Barón de Alcahalí: Diccionario biográfico de artistas valencianos, 1897, p.161

Die XXIII aprilis anno millesimo D. ${ }^{\circ} \mathrm{L}$ VIII

In Dei nomine. Amen. Noverint universi // quod ego Joannes Macip, pictor, civitatis Valencie habitator, obnimium amorem quem ergo vos Mariam Annam Boera, filiam honorabilis Petri Boera, quondam, mercatoris ville de Albayda, virginem gero sive por (...) et quia sic volo, sic iubeo, sicque mihi placet non inductus seductus nec errore aliquo circunventus sed de iuribus meis quibuscumque prout decet et convenis instructis, scienter et gratis, cum hoc presenti publico donationis instrumento ubique valituro et in aliqua unquam tempore minime violando seu revocando donatione pura, propria, simplici et irrevocabili que dicitur intervivos dono, concedo et titulo donationis trado seu quasi trado vobis eidem Marie Anne Boera, virgini, presenti et acceptanti et vestris (...) proprietate quam in pensione omnes triginta-quinque solidos censuales, rendales et annuales sive tamen laudimio et fathica sed eum toto // alio pleno iure emphiteotico et iure per ipsos percipiendo secundum forum Valencie, quos michi anno quolibet facit et respondit, facere et respondere tenetur venerabilis Petrus Sans, presbiter, vicarius temporalis ecclesie eiusdem ville de Albayda. Et quiquidem trigintaquinque solidi censuales fuerunt publico originalis carricamenti instrumento recepto per Antonium Navarro, notarium, die mercurii decima-septima septembris anno a Nativitate Domini millesimo quingentesimo quinto, venditi et originaliter carricati per venerabilem Bartolomeum Celles, rectorem ecclesie dicte ville de Albayda et Isabellam Celles, viduam, uxorem Guillermi Celles, in anno quolibet soluendi die decima-septima mensis septembris unica solutione precio vigint unius librarum eiusdem monete, Ysabelli Forner, beate, quodquidem censuale pretrerea pleno iure pro ut (...) honorabilis Vincentis // Macip, genitori meo, tamquam heredi universali eiusdem Ysabellis Forner, pro ut de dicta universali herencia dicti patris mei [instituit] ultimo dicte Ysabellis Forner testamento Valencie recepto per discretum Ludovicum Spinal, notarium, die sexta augusti dicti anni millesimi quingentesimi quinti. Et dicti testatoris decesim per eundem notarium publicato die sexta-decima februarii anni millesimi quingentesimi vigesimi primi in et cum quo heredem suum generalem instituit eundem genitorem meum, quiquidem genitor meus, postea cum suo extremo testamento Valencie condito per honorabilum et discretum Joannem Guimera, notarium, die vigesima septima decembris anno millesimo quingentesimo quadragesimo quinto. Et post dicti testatoris obitum publicato per eundem notarium die decima octobris anni millesimi quingentesimi quinquagesimi primi. Me suum proprium heredem universalem instituit et sic dictum censuale // pleno iuri mihi per tunc et pertinent. Hanc autem donationem predicti censualis cum omnibus eiusdem pensionibus et porrata, debitis et debendis, vobis facio cum omnibus eius iuribus, locis, vocibus, rationibus et actionibus, realibus et personalibus, utilibus et directos, variis sive mixtu, ordinariis et extraordinariis et aliis quibuscunque mihi et meis pertinentibus et competitivis in et super vestris que vobis et vestris dono et concedo de quibus vobis et vestris facio cessionem et concessionem. Et quibus possitis vos et vestri uti foui agere et expenri (?), agendo, conveniendo, deffendendo, ponendo, opponendo, excipiendo, replicando, tripplicando et omnia alia et singula faciendo et libere, exercendo, in iudicio et extraiudicium quecumque et quem ad modum ego facere possem sive poteram ante presentem donationem iurium que et actionum cessionem et concesionem aut nunc vel postea quando quinque instituens // inde vos et vestros in et superhiis que vobis et vestris do, dono et concedo (...) nos et potentes actores et procuratores in regni vestram propriam vosque ac vestros in locum et ius meum ponens et statuens atque confitens (...) quoque vobis dono pro vobis et vestro precario nomine tenere et possidere donec ipsorum omnium plenam, realem ac corpolarem seu quasi habueritis et aprehenderitis possessionem quam liceas vobis et vestris sive me et meis et sine auctoritate et volumtate cuiusvir iudicis vel persone sed vestra propria auctoritate et volumtate cum aprehendere et adepisti apresamque suam adeptam penes, vos et vestros licite retinere ad habendum, tenendum, vendendum, alienandum, obligandum, impignorandum, permutandum, excomunicandum et alias vestras in omnibus liberas volumtates faciendum, exceptis clericis et aliis quos forus Valencie expresse ducit scipiendos nisi dicti clerici iuxta seriem et tenorem fori novi super hoc edit bona predicta ad totam earum vitam adquirent vel haberent volens et // mandatis quod iniungatur et in (...) dictum censuale respondentibus quod ex inde respondeant et solvant vobis. Et in caso luycionis et quintamenti proprietatem pensiones et porratam dicti censualis promittens et fide bona conveniens predictam et presentem donationem et rem vole datam facere, habere et tenere et inviolabiliter observare contra cunctas personas conquerentes vel aliquid perturbantes ad forum Valencie. Et tenear actum, volo vobis et vestris de suma et legali evicitione. Huiusmodi venditionis et do omnibus damnis, misionibus, interesse et expensis littis et extralittem renuntioque: scienter, iuribus et foris dicentibus et proferentibus donationem in (...) factam ingratitudinis causam posse revocari et donatio si donatarius devenerit ad (...) per quam et testandi facultas au feratur quod talis donatio ad ipsum revertatur donatorem et quod si donatarius decesserit, prius donatore quod talis donatio (...) et omnibus aliis et quibus iuribus et foris contra hec venientibus et pro predictis omnibus et singulis sic // attendendis firmiter et complendis obligo, vobis et vestris omnia et singula bona mea, mobilia et inmobilia, privilegiata et non privilegiata, ac iura quecumque, ubique, habita et habenda. Quod est actum Valencie die vigesima tercia aprilis anno a Nativitati Domini millesima quingentesima quinquagesimo octavo.

Sig (Cruz) num mei Joannis Macip, predicti, qui hec concedo, laudo et firmo.

Testes huius rei sunt honorabilis Hieronimus Cardona et Baptista Steve, pictores, Valencie habitatoris. 


\section{5.- 1558 , abril 23. Valencia}

\section{Acuerdo entre ambas partes}

Archivo del Real Colegio del Corpus Christi de Valencia. Protocolos Notariales de Andrés Martín Pineda, n. ${ }^{\circ} 16.160$.

Iam dictus die et anno.

In Dei nomine. Amen. Cunctis pateat evidenter quod nos Joannes Macip, pictor, civitatis Valencie habitator, ex una, et Maria Anna Boera, virgo, filia honorabili Petri Boera, quondam, mercatoris ville Albayda sana per Dei gratiam, maior triginta annorum, partibus ex altera. Scienter, attendentes et considerantes quod ego dicta Maria // Anna Boera, multum tempus in domo et servicio Vincentii Macip, genitore vestri, esteti et servivi, ex quo (...) mihi debitam fuisti solidatam, in cuius solutum ipse Vincentium Macip, mihi dumsisse dictum censuale suo cum ultimo testamento legasse quoddam censuale, et ego dictus Joannes Macip, totum contrarium pretendendo dicebant et affirmabam, quod vobis dicta solidata minime dicebatur. Ideo quia vos non tamquam serva et ancilla sed vos, filia in dicti genitoris mei domo estetistis et pertracta fuistis et quod dictum censuale vobis dimissim fuit eidem genitori meo viventi redemtum et quitatum. Et sic ego sic no tenebar nec possem compelli (...) dictum censuale solvere et refficere qu... inter nos subcitate et mote fuerunt non nulli inquietudinis quia propter fuit inter nos benigniter et amicabiliter pro ut rationes cogit et imitat, quod vos dictis Joannes Macip, docetis michi quoddam censuale, pensionis triginta quinque solidorum anno quolibet die decima-septima mensis septembris unica solutione et proprietatis viginti unius // librarum, quod succedat et sit in solidum dicti censuales per quondam genitorem vestrum mihi quomodocumque et qualitercumque (...) et legati et cum sint solidate prime indomorum patris vestri et matris vestre (...) pertotum tempus quod illic steti et quod vos absolvatis me et bona mea aquibusbis rebus et negociis ac pretensionibus quas [contraremi] intemptare possitis (...) et ideo, scienter et gratis, cum hoc presenti publico instrumento ubique firmiter valitur postquam vos iamdictus Joannes Macip, donationem dicti censualis hodierna vestre instrumento recepiendo per notarium infrascriptum. Paulo ante istud confeccio mihi fecistis nos ab in vicem et vicisim, absolvimus, deffendimus, vide licet ego Joannes Macip, vos eandem Mariam Annam Boera et ego Maria Anna Boera vos prefatum Joannem Macip, presentes et acceptantes et ad invicem et vicisim ab omni actione, petitione, questione, contra vestra vel demanda quam // vel quis quam vel quas una pars nostrum contra alteram et altera contra alteram ad invicem et vicisim. Et quibusbis causis, titulis et nominibus monere, intemptari et suscitari rationibus ante dictis aut aliis quibuscumque et qualitercumque et quomodo cogitatii et incogitatiis pissimus et valedictis quibus omnibus et singulis ,scienter renumtiamus et desistimus et volumus nullus esse momenti et considerationis facientes et firmantes inter nos ad invicem et vicisim pactum speciale tam reale quam personale solemni stipulatione interveniente inmitum et conventum de ulterius aliquid non petendo, non agendo, vel conveniendo, in suo dicto et extra nulium (...) imponentes nobis et nostris in et super premissi salarium sempiternum sic quid in quocumque in iudiciario examini omnis audiencia nobis et nostris penitus denegatur. Imponentes in et super premissis nobis et nostris silencium sempiternum ac etiam imponendo super predicitis omnibus et singulis (...) ad invicem et vicissim rationibus predictis debitis aut in quibus obligatisimus et $a b(. .$.$) aquilanam stipulationem precedento // per acceptilationem subsequentem verbis legitimis interpositis.$ Iterato nos et nostros et bona nostra et nostrorum ad invicem et alternatum, absolvimus et diffinimus ac penitus liberamus pro ut melius, plenniis et utilius dici potest escribi ac etiam cogitari ad nostri et nostrorum commodum et salvamentum ac bonum et sanum et sincerum intellectum et (...) nostre voluntatis et intentionis ac vellitatis maiorem declaratiorem et firmitatem et ut ipse int (...) iusto et debito opere ne frustantur et (...) non in ducci seductione nec errore aliquo quam venti sed nostra (...) mera liberalitate de iuribus nostris ad plenum, iustum et quia sic volumus sicque nobis placet donatione pura, propria, simplici et irrevocabili que dicitur intervivos, nobis nos ad invicem et vicissim (...) donamus et tradimus seu quasi tradimus omnia qua iura omnesque actionis tam reales, personales, utiles et directas (...) mixtas, ordinarias et extraordinarias et alias quacumque // alteri nostrum contra alterum ad invicem et vicissim competentes et competentia et que in futurum competere possunt et debent nunc et in futurum directe vel in directe rationibus et causis premissis cuibus possimus uti (fieri) agere et esperiri, agendo, conveniendo, ponendo, opponendo, expiendo, repplicando, tripplicando et omnia et singula faciendo et libere exercendo in iudicio et extra iudicium quecumque et quemadum nos facere possemus sive poteramus ante presentem donationem et concessionem aut nunc vel postea quam documque instituentes inde nos ad in vicem et vicissim in et superbiis que ad invicem nobis damus et concedimus veros dominos et potentes, actores et procuratores in rem vestram propriam nos que in locum et ius nostrum alternatum ponentes et statuentes ad habendum, tenendum, vendendum, possidendum, cessionandum e transferendum et alias nostras (...) omnibus libera voluntates faciendum et renunciamus scienter iuribus, dicentibus vel proferentibus // donationem intervivos factam in gratitudinis causa posse revocari. Et si donatarius deveveris ad inopiam per quam ei libera testandi facultas aferatur, quod talis donatio ad ipsum revertatur donatorem. Et quod si donatarius decesserit prius donatore quod talis donatio (...). Et omnibus aliis iuribus et foris ac consuetudinibus iis adversantibus quoquomodo et volumus et nobis placet quod in presenti absolutione et diffinitione non intelligantur, nec comprehendantur, nec comprehendi, nec intelligi, volumus decem libre per genitricem meam dicti Joannis Macip, vobis eidem Marie Anne Boera, in contemplationem matrimonii vobis dimise et legate sed semper remaneant vobis illese. Et sic nos pro omnibus et singulis sic attendendis firmiter et complendis, obligamus ultero pars nostrum alteri et altera alteri ad invicem et vicissim omnia et singula bona nostra, mobilia et inmobilia, privilegiata et non privilegiata ac iura quecumque (...)que, habita et habenda // facimus que inde nobis fieri depremissis per notarium sub contentum hoc presens absolutionis et deffinitionis instrumentum unacuique parti nostrum tradendum. Quod est actum Valencie die viscesima tercia aprilis anno a Nativitate Domini millessimo quingentessimo quincuagessimo octavo.

Sig (Cruz ) num mei Joannis Macip. Sig (Cruz) num mei Marie Anne Boera, predictorum, qui hec singula suis singulis refferendo laudamus, concedimus et firmamus.

Testes huius rei sunt honorabilis Hieronimus Cardona et Baptista Steve, pictores, Valencie habititatores. 
6. 1558 , abril 23. Valencia

Nombramiento de procurador

Archivo del Real Colegio del Corpus Christi de Valencia. Protocolos Notariales de Andrés Martín Pineda, n. ${ }^{\circ} 16.160$

Iam dictus die et anno.

Ego Maria Anna Boera, virgo, filia honorabili Petri Boera, quondam, mercatoris, civitatis Valencie habitatori, scienter et gratis, cum hoc presenti publico procurationis instrumento, facio, constituo et solemniter ordino procuratorem meum, certum et specialem, et ad in (...) penitus generalem. Ita tamen quod vos magnificum Hieronimum (...) camerarium, // comitis de Albayda licet, absentem tamquam presentem, videlicet ad nomine meo ed pro me petendum, habendum, accipiendum et recuperandum a quibusvis collegiis, personis, universitatibus et corporibus quascumque pensiones censualem mihi tam debitas quam debendas quovis nomine et titulo quam (...)que etiam ratione sive causa ubilibet et de hiis que habueritis, etc apocam vel apocas, albaranum vel albarana, finis, absolutiones, deffinitiones et alias quasvis cautelas convenientes et opportunas vobisque benevisas faciendum fierique faciendum, concedendum et firmandum, deposite et decetero, deponendo a quibusvis curiis, tabulis, taulegeriis et depositariis, levandum et recipiendum, ac (...) isse confitendum fida (...) iuris et (...) curie, dandum et offerendum (...) et (...)bona indemnes et indemnia servandum, promittendum sub bonorum omnium et iurium meorum obligatione et ad compacendum, etc. Fiat ad littes (...) posse substituendi, etc. Generaliter, etc. Promitto, etc. Sub bonorum // et iurium meorum omnium obligatione que ad cautelam cum presenti obligo. Quod est actum Valencie, etc.

Testes huius rei sunt honorabilis Hieronimus Cardona et Baptista Steve, pictores, Valencie habitatores.

\section{EL TRONO EPISCOPAL DE LA CATEDRAL DE PALENCIA. UN ANTECEDENTE DE LOS PROGRAMAS TIPOLÓGICOS EN LAS SILLERÍAS CORALES GÓTICAS}

Las sillerías de coro góticas con decoración figurada presentan a menudo un programa iconográfico basado en las relaciones tipológicas entre Antiguo y Nuevo Testamento que refleja de una manera muy sutil las aspiraciones y deseos de la institución eclesiástica coetánea. Este programa iconográfico tiene en su base el llamado «Doble Credo», que establecía conexiones diversas entre apóstoles y profetas ${ }^{1}$.

El tema tiene un origen muy antiguo, al menos por lo que respecta al credo apostólico ${ }^{2}$. La tradición dice que fue creado el día de Pentecostés, cuando los apóstoles aportaron cada uno una frase al texto del Credo, como un resumen doctrinal básico que cada uno de ellos utilizaría en sus predicaciones por las diversas partes del mundo. Como tal aparece, en la forma que será utilizado durante todo el período medieval, en los primeros tiempos del cristianismo, con diversas redacciones y asignaciones de textos a los apóstoles.

Desde el siglo xII el Credo de los apóstoles aparece relacionado con el Credo de los profetas, constituyéndose lo que se denomina comúnmente «Doble credo». De este modo a cada frase atribuida a un apóstol se le contrapone otra de las contenidas en cada uno de los libros proféticos, generalmente relacionadas entre sí y con el objetivo de ver en la segunda un antecedente o anuncio del hecho al que se alude en la primera.

Programas iconográficos derivados de esta relación fueron ampliamente utilizados en obras de arte, sobre todo en el último período gótico.

Algunas características del tema como la clara división en dos grupos de las figuras representadas y la relación desigual entre ambas, con preeminencia de unas sobre las otras, supusieron un uso especialmente abundante del doble credo en las sillerías corales, que presentaban en su configuración estructural dos partes o niveles claramente diferenciados (la sillería alta

1 P. Lacroix y A. Renon, «Apôtres et Prophètes au Credo: un thème iconographique entre le rayonnement et l'oubli», Pensée, image et communication en Europe médiévale. A propos des stalles de Saint-Claude, Besançon, 1993, pp. 83-100. M. A. Franco Mata, «El "Doble Credo" en el arte medieval hispánico», Boletín del Museo Arqueológico Nacional, XIII (1995), pp. 119-136. 